\title{
A Decision Support System to Optimise Fertigation Management in Greenhouse Crops
}

\author{
L. Incrocci, D. Massa and A. Pardossi ${ }^{\mathrm{a}}$ \\ Dip. Biologia delle Piante Agrarie \\ University of Pisa \\ Pisa \\ Italy
}

\author{
L. Bacci, P. Battista, B. Rapi and M. Romani \\ Institute of Biometeorology (IBIMET) \\ National Research Council \\ Firenze \\ Italy
}

Keywords: closed system, hydroponics, modelling, soilless culture, tomato

\begin{abstract}
Optimal operation of greenhouse crops requires an appropriate management of fertigation, especially when the availability and/or the quality of irrigation water are limited and/or there are environmental constraints, such as those derived from Nitrate Directive in Europe. The paper illustrates the main features of a decision support system (DSS) for the fertigation management in soilless culture, which is still under development in the framework of the European research project EUPHOROS. The DSS modules provide information on the optimal irrigation regime (based on the static hydrological properties of the growing medium) and on crop water and nutrients requirements (including both plant uptake and leaching requirement in open and semi-closed growing systems). An easy-to-use nutrient solution calculator and an extendable crop database have been integrated in the DSS. The DSS can assist the grower in daily operational management of fertigation as well as for off-line (prior-to-planting) simulation, for instance to compare - in terms of water and nutrients use efficiency - different fertigation strategies, growing system layouts, water qualities and/or crop species (analysis of the scenario). An example of such simulation is provided for tomato grown under saline conditions.
\end{abstract}

\section{INTRODUCTION}

The advantages of soilless culture over conventional soil cultivation (e.g., higher use efficiency of water, nutrients, labour etc.; better product quality) are fully achievable only in closed systems where nutrient effluents are recirculated (Stanghellini et al., 2007). However, the management of closed systems is more difficult due to the risk of rootborne diseases and the possible accumulation of non-essential ions in the recirculating Nutrient Solution (NS) (Pardossi et al., 2006). When poor quality irrigation water (e.g., saline water) is available, the progressive accumulation of ballast ions (such as $\mathrm{Na}$ and $\mathrm{Cl}$ ) scarcely absorbed by the crop makes it necessary to discharge the recirculating NS (flushing) with consequent waste of water and fertilizers (i.e., semi-closed systems). In these systems, the knowledge of the recirculating NS composition is a key factor to optimize the fertigation management, in particular to decide when flushing is necessary, based on physiological and/or environmental criteria, e.g. taking in account of the limits imposed to the concentration of pollutants (e.g., $\left.\mathrm{NO}_{3}\right)$ in the wastewater discharged to surface water by the legislation derived from European Nitrate Directive (The Council of the European Communities, 1991).

In the framework of the European research project EUPHOROS (http://www. euphoros.wur.nl/UK/), work is in progress to develop a decision support system (DSS) for the management of fertigation of greenhouse crops (Hydrotool). This paper illustrates the general structure of Hydrotool and reports the results of the validation of the models implemented in the DSS in order to simulate crop water and mineral relations. An example of the possible use of DSS for analysis of scenarios (different strategies for fertigation) is also reported.

\footnotetext{
a alberto.pardossi@agr.unipi.it
} 


\section{MATERIALS AND METHODS}

\section{DSS Structure and Algorithms}

Hydrotool is a modular system developed in C\# Microsoft .Net Frameworks 3.5. Default language is currently English (US), but the system will support other languages such as Italian and Spanish. The DSS is composed of a central database containing all input and output data to or from the different subroutines (Fig. 1). Graphical and statistical tools have been implemented for data analysis and reporting. The DSS incorporates three main modules (Fig. 1): 1) nutrient solution calculation; 2) evapotranspiration (ET) simulation; and 3) fertigation management (on- and off-line).

1. Nutrient Solution Calculation. The module (Fig. 2) calculates the composition and the cost of the nutrient stocks based on: i) the ion composition of irrigation water; ii) the crop fertigation recipe (i.e., $\mathrm{pH}, \mathrm{EC}$ and the concentrations of all nutrients delivered to the crop); iii) technical characteristics and prices of fertilisers, acids and bases; iv) technical characteristics of the fertigation device (i.e., volume of stock tanks and dilution ratio). The module contains a pre-compiled database with the characteristics of the main fertilisers used for soilless culture and several nutrient solution recipes for the main greenhouse crops. Obviously, the database can be extended by the grower, who may include his/her own recipes and/or fertilisers. The occurrence of salt precipitations due to an excessive salt concentration in the nutrient stocks is also verified by the NS calculator.

2. ET Simulation. ET can be provided directly by the user or estimated from weather data using different simplified equations such as those proposed by De Villele (1974), De Graaf (1988) and Baille et al. (1994). These models require the knowledge of Leaf Area Index (LAI) evolution, which can be provided by the user or simulated as a function of thermal time calculated automatically using weather data and the base temperature for the crop of interest.

3. Fertigation Management. This module is based on some algorithms originally developed and reported in detail in previous works (Carmassi et al., 2007; Incrocci et al., 2008; Massa et al., submitted). It simulates the variation of the ion concentration in the NS that is drained out from open systems or recirculated in semi-closed systems. In the latter systems, the user can select the strategy for nutrient replenishment among three possible options (Fig. 3; Massa et al., 2010), which are briefly described below:

Strategy A1. ET is compensated in the mixing tank with refill NS at pre-established EC and ion composition. Due to the possible accumulation of ballast and nutrient ions contained in the irrigation water at concentrations higher than uptake concentrations $\left(\mathrm{C}_{\mathrm{U}}\right.$; it is the ion/water uptake ratio), the EC of the recirculating NS tends to rise up starting from a pre-fixed EC set point. When the maximum EC value tolerated by the crop is reached, the NS in the mixing tank must be discharged.

Strategy A2. ET is compensated with refill NS as in Strategy A1. However, when the ceiling EC is reached, the mixing tank is refilled with only (acidified) raw water till $\mathrm{N}-\mathrm{NO}_{3}$ concentration is lower than a physiological or environmental limit (e.g., maximum nitrate concentration of $1.0 \mathrm{~mol} \mathrm{~m}$, according to Italian legislation on the wastewater discharge in the environmental). Afterwards, NS is discharged as described for Strategy A1.

Strategy B. ET is compensated with a refill NS that has a variable ion composition adjusted in order to maintain a determined EC of the recycling NS. Due to progressive $\mathrm{NaCl}$ accumulation in the recirculating water, the macronutrient content tends to decrease until ${\mathrm{N}-\mathrm{NO}_{3}}_{3}$ concentration drops below a critical concentration; afterward, NS is discharged as described for Strategy A1 and A2.

The DSS can be run in two different modes:

- Off-line (prior to planting): to predict crop water and nutrient requirements based on water quality, climate, possible legislative constraints and a number of parameters regarding crop physiology (i.e., plant mineral $\mathrm{C}_{U}$ ), the layout of growing systems (i.e., the volume of recirculating NS in the growing system) and fertigation regime (i.e., the strategy for nutrient replenishment, as previously described); 
- On-line (real-time): to estimate the ion concentrations in the recirculating NS in semiclosed soilless systems.

For both on- and off-line simulation the following input variables and parameters are recovered from the database (default data or results from other modules, e.g., NS or ET calculator) or inserted directly by the user in the summary panel:

- Ion composition of irrigation water and reference NS;

- Technical data about growing systems (i.e., water or substrate culture), the volume of water compartments (mixing tank, drainage tank, substrate water capacity etc.);

- Crop data such as $\mathrm{C}_{\mathrm{U}}$, maximum or minimum EC and/or concentration of a given ion tolerated by the crop (for the whole growing cycle or different growth stages);

- Environmental constraints (i.e., the maximum allowed concentration of polluting ions in the wastewater).

The DSS has been developed for tomato culture, but it can be used for any crop as long as the required input parameters are available.

\section{RESULTS AND DISCUSSION}

\section{Model Validation}

Some experiments were conducted with greenhouse tomato from the 2005 to 2010 for calibration and validation of the sub-models implemented in the DS. This study has been reported in details a paper published recently (Massa et al., 2011).

Simulations were run by using an empirical crop nutrient uptake model based on the concept of $\mathrm{C}_{\mathrm{U}}$. Although it could appear weak as compared with the use of mechanistic models (Le Bot et al., 1998), the concept of $\mathrm{C}_{\mathrm{U}}$ has many advantages for the practical management of greenhouse crops (Savvas, 2002; Gallardo et al., 2009), e.g. onfarm calibration. In fact, the $\mathrm{C}_{\mathrm{U}}$ of different nutrients could be determined directly by the grower (by measuring ET and the concentration of NS by quick tests) and used to recalibrate the model.

For the sake of brevity, we report here only the results for a semi-closed system that was managed using saline water $\left(9 \mathrm{~mol} \mathrm{~m}^{-3} \mathrm{NaCl}\right)$ and following strategy $\mathrm{A} 1$. The model predicted acceptably the time course of EC and ion concentrations in the recirculating or drainage NS (Fig. 4). In most cases, the simulations of seasonal crop water uptake were within the confidence interval of the measurements with a maximum deviation of $+6 \%$. Although the model underestimated the seasonal volume of drainage water in some cultures, in general there was a good agreement between simulations and observations in total use of nitrogen.

\section{Off-Line Simulation}

The aggregated model implemented in the fertigation manager could be used for the analysis of scenarios, for instance to compare, in terms of water and nutrient use efficiency and/or environmental impact, different fertigation control procedures, system layouts (e.g., differing for the ratio between the volume of recirculating NS and the capacity of mixing tank), water qualities and crop species (with diverse nutrient requirements, salt tolerance and/or affinity to the ballast ions contained in irrigation water). In some countries, such as The Netherlands, the legislation imposes to greenhouse growers a maximum annual amount of irrigation water depending on the crop (e.g., 1140 $\mathrm{L} \mathrm{m}^{-2}$ for tomato; Stanghellini et al., 2007). Any model able to estimate both ET and leaching requirement (LR, the ratio between drainage water and ET) could be a useful tool to both growers (for an efficient water management at farm level) and policy makers (e.g., to establish the proper limits to the use of water and/or fertilisers).

An example of such simulation is reported in Figure 5, which shows the effects of different $\mathrm{NaCl}$ concentration $\left(0-10 \mathrm{~mol} \mathrm{~m}^{-3}\right)$ in the irrigation water on LR, water use efficiency (WUE) and $\mathrm{N}-\mathrm{NO}_{3}$ leaching in semi-closed cultures of greenhouse tomato conducted with different fertigation strategies. For the simulation, we assumed that both $\mathrm{ET}$ and fruit yield were not significantly affected either by $\mathrm{EC}$ and $\mathrm{NaCl}$ levels (in the 
considered range) or by the short-term nutrient starvation resulting from the application of Strategy A2. These assumptions were verified in previous experiments with greenhouse tomato (Massa et al., 2010). Siddiqi et al. (1998) found that neither the reduction of macronutrient concentration to 50 or $25 \%$ of full-strength NS nor the interruption of nutrient replenishment for the last two weeks of cultivation influenced significantly fruit yield and quality in greenhouse tomato plants grown in closed substrate culture. In open rockwool culture of tomato, Le Bot et al. (2001) observed a reduction in fruit yield only four weeks after the interruption of $\mathrm{N}$ supply.

Our simulation indicates that increasing the salinity of irrigation water results in a proportional increase in $\mathrm{LR}$ and $\mathrm{N}-\mathrm{NO}_{3}$ leaching due to faster $\mathrm{NaCl}$ accumulation in the recirculating NS and, consequently, the higher frequency of discharge (Fig. 5). Simulation also indicates that Strategy A2 provides the highest WUE and minimizes the environmental impact associated to $\mathrm{N}-\mathrm{NO}_{3}$ leachate.

Another possible application of the off-line fertigation manager is to estimate the emission of plant protection products applied through recirculating NS, which depends on the dissipation kinetics and the root uptake of the substance under consideration and, evidently, on the frequency of NS discharge (Van der Linden, 2009).

\section{CONCLUSIONS}

The NS calculator implemented in Hydrotool is a user-friendly program that can be run for professional use, also providing a set of nutritive recipes to the benefit of less expert users. This module is essential in the DSS to calculate the desired refill NS composition that is used by fertigation manager to simulate the evolution of ion concentrations in the recirculating NS during the cultivation.

The application of ET simulation and on-line fertigation manager makes it possible to predict the crop behaviour during the cultivation for accurate management of nutrient replenishment (i.e., the need for flushing, the nutrient concentration of the refill NS, etc.) with the aim to increase the use efficiency for both water and fertilisers. The simulation can provide an early warning system for crop stress (e.g., due to excessive concentration) or technical breakdown. For example, the continuous comparison between simulated and actual EC of the recirculating NS may indicate a failure of fertigation system. Off-line simulation can assist the grower in his/her decision about structural investments (e.g., the installation of a reverse-osmosis system), the selection of crop species and water source, the fertigation strategy based on physiological (e.g., salinity tolerance) and/or environmental constraints.

The use of simple parameters for simulation, such as $\mathrm{C}_{\mathrm{U}}$, is a key factor for the operative use of Hydrotool. Further development of Hydrotool will regard the implementation of a growth-based mineral uptake model that, combined with ET simulator, will be able to predict the variation of $\mathrm{C}_{\mathrm{U}}$ during the crop development, as recently proposed by Gallardo et al. (2009).

\section{ACKNOWLEDGEMENTS}

This work was funded by the European Commission, Directorate General for Research $\left(7^{\text {th }}\right.$ Framework RTD Programme; Project EUPHOROS $)$.

\section{Literature Cited}

Baille, M., Baille, A. and Laury, J.C. 1994. A Simplified Model for Predicting Evapotranspiration Rate of 9 Ornamental Species Vs Climate Factors and Leaf-Area. Sci. Hort. 59:217-232.

Carmassi, G., Incrocci, L., Maggini, R., Malorgio, F., Tognoni, F. and Pardossi, A. 2007. An aggregated model for water requirements of greenhouse tomato grown in closed rockwool culture with saline water. Agri. Water Manage. 88:73-82.

De Graaf, R. 1988. Automation of water supplied of glasshouse crops by means of calculating the transpiration and measuring the amount of drainage water. Acta Hort. 229:219-231. 
De Villele, O. 1974. Besoins en eau des cultures sous serres. Essai de conduite des arrosa ges en function de l'ensoleillement. Acta Hort. 35:123-135.

Gallardo, M., Thompson, R.B., Rodriguez, J.S., Rodriguez, F., Fernandez, M.D., Sanchez, J.A. and Magan, J.J. 2009. Simulation of transpiration, drainage, N uptake, nitrate leaching, and $\mathrm{N}$ uptake concentration in tomato grown in open substrate. Agri. Water Manage. 96:1773-1784.

Incrocci, L., Massa, D., Carmassi, G., Maggini, R., Bibbiani, C. and Pardossi, A. 2008. SIMULHYDRO, a simple tool for predicting water use and water use efficiency in tomato soilless closed-loop cultivations. Acta Hort. 801:1005-1011.

Le Bot, J., Adamowicz, S. and Robin, P. 1998. Modelling plant nutrition of horticultural crops: a review. Sci. Hort. 74:47-82.

Le Bot, J., Jeannequin, B. and Fabre, R. 2001. Growth and nitrogen status of soilless tomato plants following nitrate withdrawal from the nutrient solution. Ann. Bot. 88:361-370.

Massa, D., Incrocci, L., Maggini, R., Carmassi, G., Campiotti, C.A. and Pardossi, A. 2010. Strategies to decrease water drainage and nitrate emission from soilless cultures of greenhouse tomato. Agri. Water Manage. 97:971-980.

Massa, D., Incrocci, L., Maggini, R., Bibbiani, C., Carmassi, G., Malorgio, F. and Pardossi, A. 2010. Simulation of crop water and mineral relations in greenhouse soilless culture. Envi. Modell. Soft. 26:711-722.

Pardossi, A., Malorgio, F., Incrocci, L., Carmassi, G., Maggini, R., Massa, D. and Tognoni, F. 2006. Simplified models for the water relations of soilless cultures: what they do or suggest for sustainable water use in intensive horticulture. Acta Hort. 718:425-434.

Savvas, D. 2002. Automated replenishment of recycled greenhouse effluents with individual nutrients in hydroponics by means of two alternative models. Biosyst. Eng. 83:225-236.

Siddiqi, M.Y., Kronzucker, H.J., Britto, D.T. and Glass, A.D.M. 1998. Growth of a tomato crop at reduced nutrient concentrations as a strategy to limit eutrophication. J. Plant Nutr. 21:1879-1895.

Stanghellini, C., Pardossi, A. and Sigrimis, N. 2007. What limits the application of wastewater and/or closed cycle in horticulture? Acta Hort. 747:323-330.

The Council of the European Communities, 1991. Council Directive of 12 December 1991 concerning the protection of waters against pollution caused by nitrates from agriculture sources (91/676/EEC). Off. J. Eur. Communities, L 375.

Van der Linden, A.M.A. 2009. Emissions by "other routes than air" from protected crop systems. Technical report to EFSA under procurement NP/EFSA/PPR/2008/04. http://www.efsa.europa.eu/en/scdocs/scdoc/10e.htm. 


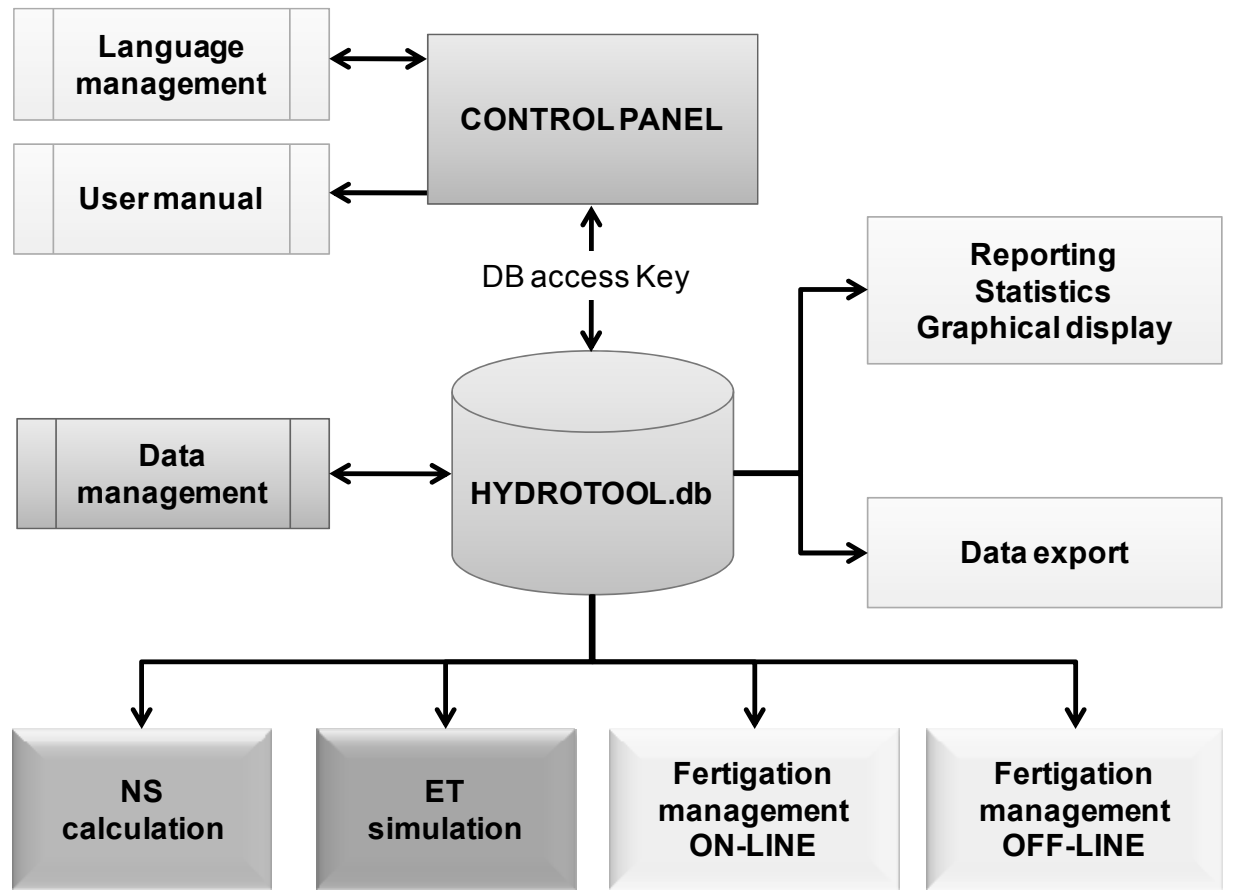

Fig. 1. Schematic description of Hydrotool. Four main modules are used for the calculation of the composition of the nutrient solution (NS), the simulation of crop evapotranspiration (ET) and off- or on-line fertigation management of open and semi-closed greenhouse soilless systems. 


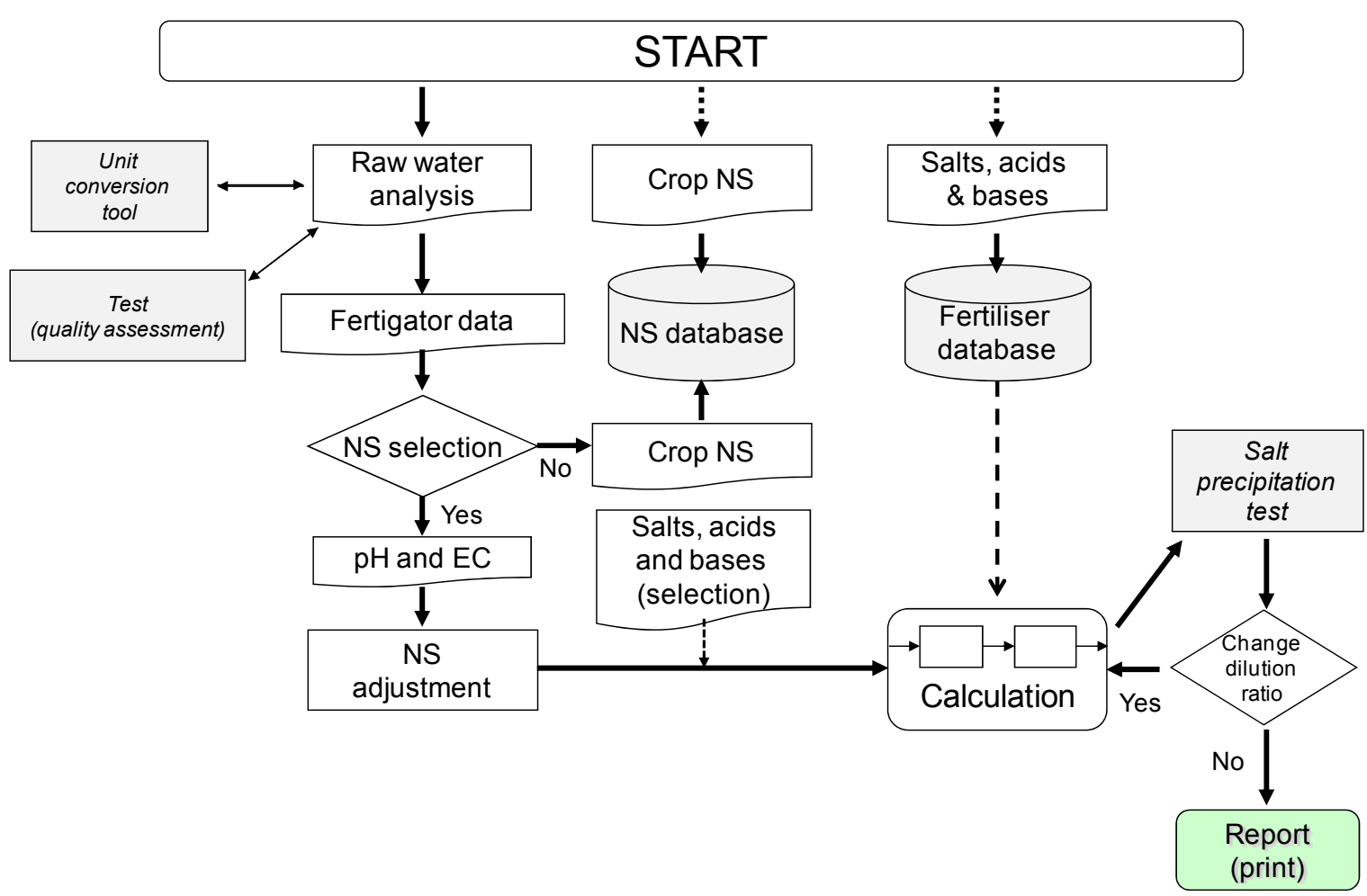

Fig. 2. Schematic description of the Nutrient Solution (NS) calculator implemented in the DSS Hydrotool. The module calculates the composition and the cost of nutrient stocks based on a series on user's inputs. An extendable database contains the characteristics of the main fertilisers and NS recipes used for greenhouse soilless crops. The possible salt precipitations due to an excessive salt concentration in the nutrient stocks are also checked by the NS calculator.
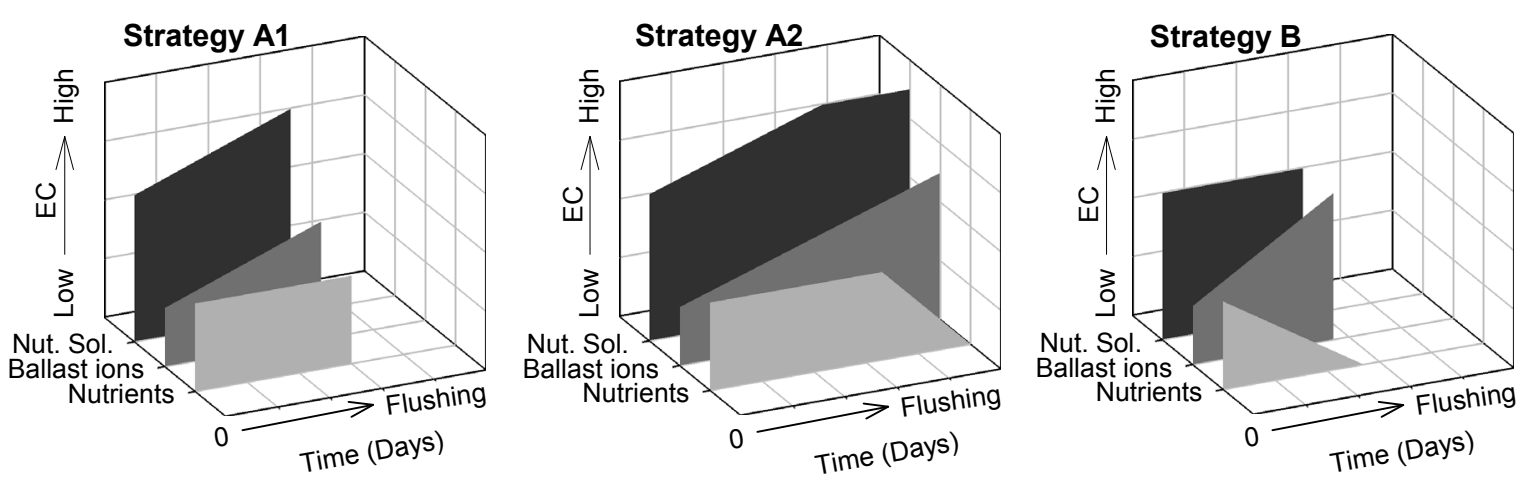

Fig. 3. Schematic description of the time-course of the EC in the recirculating nutrient solution (NS) and the contribution to EC from nutrients and $\mathrm{NaCl}$ in semi-closed soilless cultures conducted with three different fertigation strategies. NS is discharged whenever EC reaches a pre-set ceiling value (strategy A1) and, concurrently, the $\mathrm{N}-\mathrm{NO}_{3}$ concentration is lower than a physiological or environmental limit (e.g., $1.0 \mathrm{~mol} \mathrm{~m}^{-3}$, according to Italian legislation on the discharge of wastewater) (strategy A2). The latter is the only condition to be fulfilled for the discharge in strategy B. It is expected that, in the same soilless culture, the different strategies result in different frequency of flushing, which is indicated (approximately) by the value on the abscissa. 

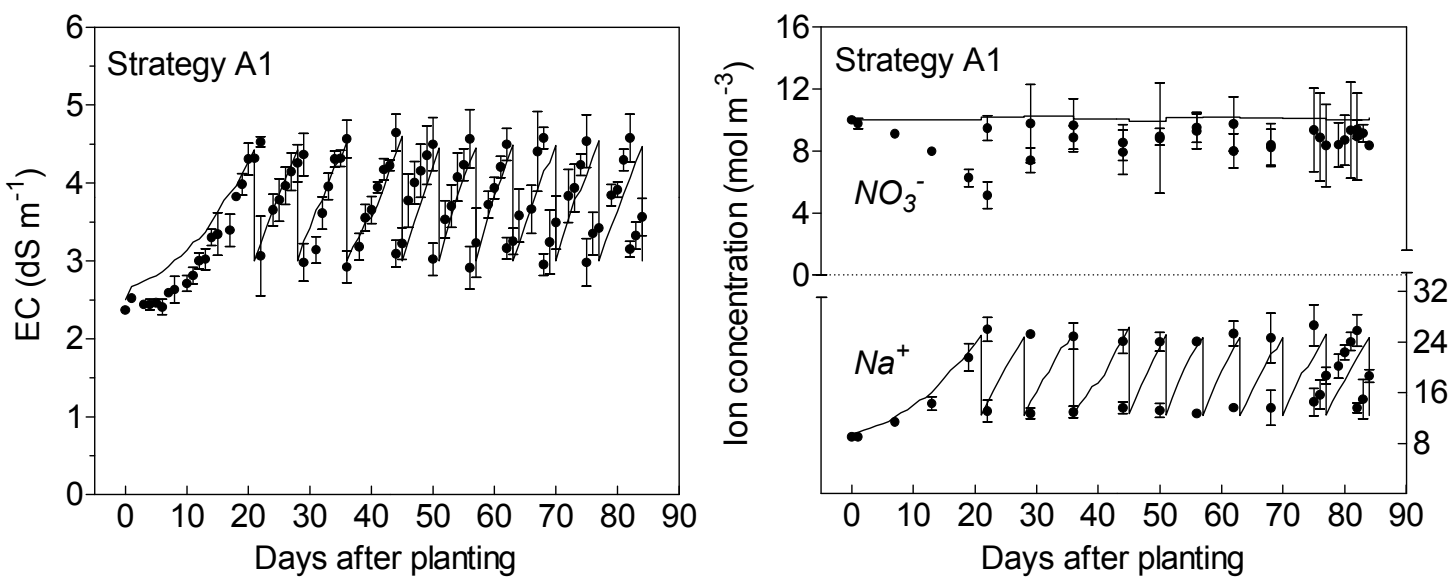

Fig. 4. Measured (symbols) and simulated (lines) $\mathrm{EC}$ and concentration of $\mathrm{N}-\mathrm{NO}_{3}$ and $\mathrm{Na}$ in the recirculating nutrient solution (NS) in soilless cultures of greenhouse tomato (Solanum lycopersicum L. 'Jama'). Fertigation was controlled following strategy A1 as described in Figure 3. The spikes of rapid decline in EC and $\mathrm{Na}$ concentration correspond to the flushing events (10 in total). The tomato culture was conducted for 84 days in the spring of 2005 using irrigation water containing $9.0 \mathrm{~mol} \mathrm{~m}^{-3} \mathrm{NaCl}_{\text {. }}$ The EC of the refill NS and the ceiling EC for flushing was 2.70 and $4.5 \mathrm{dS} \mathrm{m}^{-1}$, respectively.
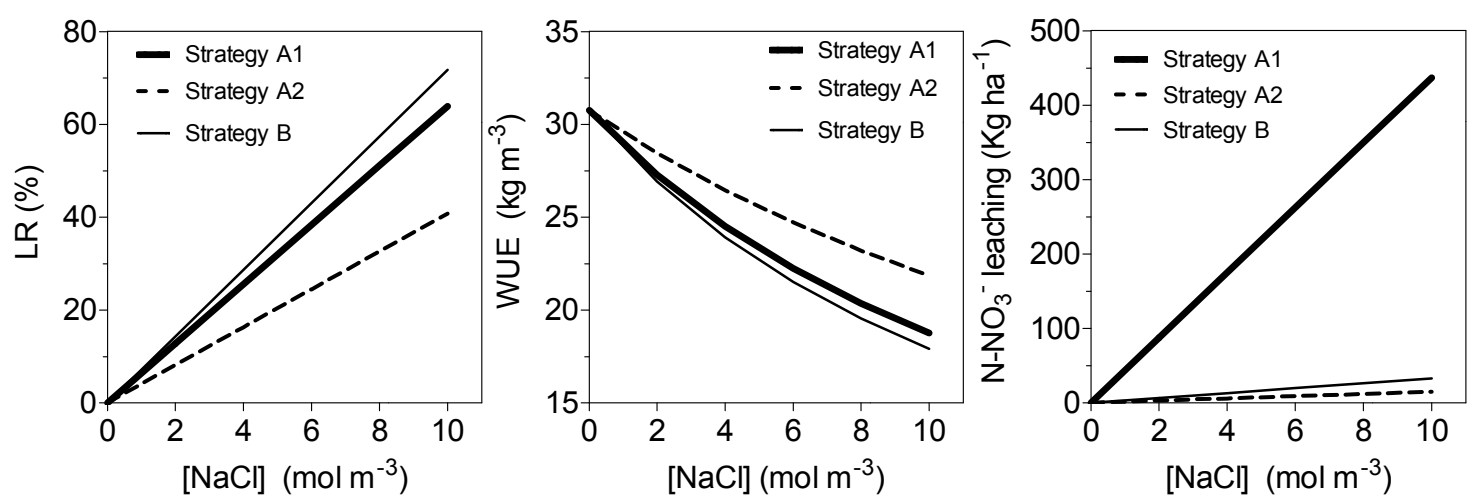

Fig. 5. Simulated leaching requirement (LR; drainage water/evapotranspiration percent ratio), water use efficiency (WUE) and $\mathrm{N}-\mathrm{NO}_{3}$ leaching in tomato cultures carried out with different fertigation strategies (see text and Figure 3 for description) and $\mathrm{NaCl}$ concentrations in the irrigation water. In all systems, the nutrients contribution to the EC of the refill nutrient solution (NS) was $1.5 \mathrm{dS} \mathrm{m}^{-1}$ and their nutrient concentrations were equal to corresponding nutrient uptake concentration (i.e., the ratio between the nutrient and water crop uptake). In strategy A, NS was discharged whenever its EC reached an EC of $1.0 \mathrm{dS} \mathrm{m}^{-1}$ higher than the EC of refill NS (A1) and, concurrently, the $\mathrm{N}^{-\mathrm{NO}_{3}}$ concentration was lower than $1.0 \mathrm{~mol}$ $\mathrm{m}^{-3}$ (A2). In strategy B, NS was discharged when the $\mathrm{N}^{-N}{ }_{3}$ concentration was lower than $1.0 \mathrm{~mol} \mathrm{~m}^{-3}$. Total volume of recycling NS (substrate and mixing tank), crop evapotranspiration and fruit yield were $75.0 \mathrm{~m}^{3} \mathrm{ha}^{-1}, 6500 \mathrm{~m}^{3} \mathrm{ha}^{-1}$ and $200 \mathrm{t}$ $\mathrm{ha}^{-1}$, respectively. 